\title{
Utilization of Macadamia Nutshell Residue for the Synthesis of Magnetic Activated Carbon toward Zinc (II) Ion Removal
}

\author{
Minh-Trung Dao $\mathbb{D}^{1},{ }^{1}$ Thi-Phuong-Linh Tran $\mathbb{D}^{1},{ }^{1}$ Duc-Thuong Vo $\mathbb{D}{ }^{1}$ \\ Van-Kieu Nguyen $\mathbb{D}^{2,3}$ and Le-Thuy-Thuy-Trang Hoang $\mathbb{D}^{1}$ \\ ${ }^{1}$ Department of Environmental Engineering, Thu Dau Mot University, Binh Duong, Vietnam \\ ${ }^{2}$ Institute of Fundamental and Applied Sciences, Duy Tan University, Ho Chi Minh City 700000, Vietnam \\ ${ }^{3}$ Faculty of Natural Sciences, Duy Tan University, Da Nang 550000, Vietnam \\ Correspondence should be addressed to Minh-Trung Dao; trungdm@tdmu.edu.vn, Van-Kieu Nguyen; \\ nguyenvankieu2@duytan.edu.vn, and Le-Thuy-Thuy-Trang Hoang; tranghltt@tdmu.edu.vn
}

Received 19 June 2021; Revised 14 July 2021; Accepted 4 September 2021; Published 21 September 2021

Academic Editor: Ştefan Ţălu

Copyright (c) 2021 Minh-Trung Dao et al. This is an open access article distributed under the Creative Commons Attribution License, which permits unrestricted use, distribution, and reproduction in any medium, provided the original work is properly cited.

\begin{abstract}
In this study, macadamia nutshell residue, a prevalent leftover and green agricultural waste in Vietnam, was utilized to prepare a magnetic activated carbon adsorbent. The obtained material was characterized by its surface functionalities, elemental com-

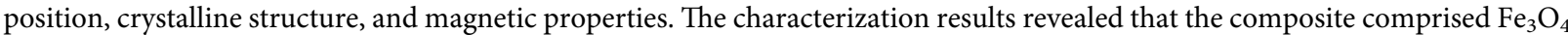
nanoparticles attached to the carbon matrix. The saturation magnetization $\left(M_{s}\right)$ of the composite was found to be $38.2 \mathrm{emu} \mathrm{g}^{-1}$, indicating a convenient separation of the solid adsorbent from aqueous media using an external magnetic field. The feasibility of removing zinc (II) ion from an aqueous solution of the activated carbon/ $/ \mathrm{Fe}_{3} \mathrm{O}_{4}\left(\mathrm{AC} / \mathrm{Fe}_{3} \mathrm{O}_{4}\right)$ composite was examined. The adsorption kinetics were best explained by the Elovich model and the pseudo-second-order model. The adsorption capacity at equilibrium and the initial rate of $\mathrm{Zn}^{2+}$ adsorption determined by the pseudo-second-order model were $22.73 \mathrm{mg} \mathrm{g}^{-1}$ and $4.18 \mathrm{mg} \mathrm{g}^{-1} \mathrm{~min}^{-1}$, respectively. The implications of this study are that a low-cost, green, and magnetically separable material prepared by a large-scale available solid waste can be a promising adsorbent for the elimination of heavy metals.
\end{abstract}

\section{Introduction}

Ceaseless industrialization and population growth across the world have led to a severe deterioration in water quality [1]. The use of chemicals and industrial compounds has continued to increase, posing a significant pollution risk to existing watercourses. Water pollution is a global environmental challenge that destroys the food sources and contaminates drinking water, leading to immediate and long-term effects on human health [2]. Many water pollutants are reported to act as toxic chemicals, including dyes, antibiotics, heavy metals, fertilizers, and pesticides $[1,2]$. Heavy metal pollution is a major water pollution hazard and presents a serious risk to human health and aquatic environments $[3,4]$. The release wastewater can contain various heavy metals, for instance, nickel, mercury, lead, cadmium, zinc, arsenic, and copper [5]. Zinc is among the metals that have a widespread use in galvanization, electroplating, and the manufacture of alloys, allowing it to accumulate in the environment [6]. This element is essential for living organisms as playing a central role in the immune system and taking part of many metal-enzymes and metal-proteins; however, its excess in water can cause eminent health problems, such as stomach cramps, skin irritations, vomiting, nausea, and anemia $[6,7]$. Therefore, for many nations, the search for effective heavy metal treatments, especially for zinc ion, is a priority among their environmental and sustainable development strategies.

In order to eliminate heavy metals, various physicochemical techniques have conventionally employed, including chemical precipitation [8], coagulation and flocculation [9], electrochemical method [10], adsorption 
[11], ion exchange [12], and reverse osmosis [12]. Among them, adsorption has attracted considerable attention from scientists due to its cost-effectiveness, environmental friendliness, and easy operation [13, 14]. Many adsorbents have been developed, including zeolite [15], metal-organic frame materials [16], layered double hydroxides [14], graphene [13], nano- and mesoporous silica [17], and activated carbon (AC) [18]. In particular, AC is popular and widely applied due to its chemical stability, high surface area, and microporous structure [19]. However, the use of commercial $\mathrm{AC}$ has the disadvantage of being expensive due to the relatively high cost of its starting materials (wood or coal) [20]. Thus, it is highly desirable to prepare a low-cost, efficient, and locally available activated carbon, derived from renewable biomass materials [21]. Macadamia nuts, a highvalue agricultural product, have been grown worldwide since they were first discovered in Australia in 1857. Approximately $70-77 \%$ of a macadamia nut comprises its shell. With the rapidly increasing demand for macadamia kernels across the globe, their leftover nutshells have come to represent a large amount of solid residue, creating a serious waste disposal problem. One promising process of recycling macadamia nutshells is to produce biochar, which can be used either for heating purposes or to prepare activated carbon thanks to these shells' high level of carbon content [22]. However, whereas the role of other agricultural wastes in producing $\mathrm{AC}$ has been extensively investigated, macadamia nutshell residue has received limited attention [23]. Moreover, in Vietnam, there remains little study on the potential of macadamia nutshells as AC-based materials even though the production of these nuts has increased rapidly here each year.

The use of $A C$ in water treatments has also faced difficulties in the recovery of solid adsorbents from aqueous media [24]. In recent years, a combination of magnetic materials and $\mathrm{AC}$ to facilitate the separation via the use of an external magnetic field has emerged as an economic and efficient choice to offset this problem [24, 25]. AC/iron oxide composites are among the magnetically separable adsorbents that serve as effective adsorbents for heavy metals removal [26]. To the best of our knowledge, the study on magnetic AC sorbent for removal of zinc (II) ion is still limited. Therefore, the work reported here sought to prepare an $\mathrm{AC} / \mathrm{Fe}_{3} \mathrm{O}_{4}$ composite derived from Vietnamese macadamia nutshell residue in order to explore its feasibility for zinc (II) ion removal. The structural, textural, and magnetic properties of the synthesized material were characterized. The effects of initial $\mathrm{pH}$, adsorbent dose, adsorption kinetics, and adsorption mechanism were also determined.

\section{Materials and Methods}

2.1. Materials. The chemicals used were ferrous sulfate heptahydrate $\left(\mathrm{FeSO}_{4} .7 \mathrm{H}_{2} \mathrm{O}\right)$, iron(III) chloride hexahydrate $\left(\mathrm{FeCl}_{3} \cdot 6 \mathrm{H}_{2} \mathrm{O}\right)$, sodium hydroxide $(\mathrm{NaOH})$, hydrochloric acid $(\mathrm{HCl})$, and anhydrous potassium carbonate $\left(\mathrm{K}_{2} \mathrm{CO}_{3}\right)$. They were analytical grade and supplied by Merck, Germany. Macadamia nutshell residue was collected as biomass waste in Bao Lam district, Lam Dong province, Vietnam.
2.2. Synthesis of AC from Macadamia Nutshells Using K2CO3. AC derived from macadamia nutshells was synthesized based on the method of Dao et al. [27]. Typically, the cleaned and dried nutshells were mechanically ground into a powder. They were then immersed in $\mathrm{K}_{2} \mathrm{CO}_{3}$ solution for $24 \mathrm{~h}$ using an impregnation of 1.0. The impregnation ratio was the weight of $\mathrm{K}_{2} \mathrm{CO}_{3}$ to the weight of the macadamia nutshells. The obtained solid was washed with deionized water and calcined at $650^{\circ} \mathrm{C}$ for $1 \mathrm{~h}$. The fine powder was then stored in a vacuum for subsequent experiments. The whole preparation process of magnetic AC is illustrated in Figure 1.

2.3. Synthesis of Magnetic AC. The synthesis of magnetic AC was performed based on the method of Han et al. [28], with some modifications. Typically $100 \mathrm{~mL}$ of $0.13 \mathrm{M}$ ferrous sulfate and $100 \mathrm{~mL}$ of $0.25 \mathrm{M}$ ferric chloride solutions were mixed to obtain an $\mathrm{Fe}^{2+} / \mathrm{Fe}^{3+}$ molar ratio of $1: 2$. Subsequently, AC $(5 \mathrm{~g})$ was added, and the mixture was heated to $65^{\circ} \mathrm{C}$. Having cooled the mixture to $40^{\circ} \mathrm{C}, 5 \mathrm{M}$ sodium hydroxide solution was added until the solution's $\mathrm{pH}$ reached 10.0. After stirring for another $1 \mathrm{~h}$, the mixture was impregnated overnight. The precipitate was then washed with deionized water until a $\mathrm{pH}$ of 7 was reached and dried at $80^{\circ} \mathrm{C}$.

2.4. Material Characterizations. The crystalline phases of the composite were identified via X-ray diffraction (XRD) using an X-ray diffractometer (Equinox 5000, Thermo Scientific, France) equipped with a $\mathrm{Cu} \mathrm{K} \alpha$ radiation source $(\lambda=1.5406 \AA)$. The diffractometer was set at an accelerating voltage of $35 \mathrm{kV}$, an applied current of $25 \mathrm{~mA}$, and the step size of 0.015 . The surface morphology of the materials and elemental mapping were monitored by scanning electron microscopy equipped with an energy dispersive X-ray (SEMEDX; S4800, Hitachi, Japan, at 1.0-5.0 keV). Transmission electron microscopy (TEM) images were obtained using a JEOL JEM-1010 microscope, Japan, at $80 \mathrm{kV}$. The Fouriertransform infrared spectroscopy (FTIR) spectra were recorded using an FTIR/NIR spectrometer (Frontier/PerkinElmer, USA). The specific surface areas of the materials were measured via the $\mathrm{N}_{2}$ adsorption-desorption method using a Micromeritics-TriStar II Plus instrument.

2.5. Adsorption Experiments. The adsorption of zinc ion on magnetic AC was carried out using batch experiments. Each bottle containing $15 \mathrm{mg}$ adsorbents and $50 \mathrm{~mL}$ metal ion solution was stirred at $150 \mathrm{rpm}$. All the experiments were conducted in triplicate with an initial $\mathrm{Zn}^{2+}$ concentration of $25 \mathrm{ppm}$. The sample solutions were collected by separating the solid through centrifugation. The effect of the solution $\mathrm{pH}$ (adsorbent dose of $0.3 \mathrm{~g} \mathrm{~L}^{-1}$ and adsorption time of $60 \mathrm{~min}$ ) was studied in the initial $\mathrm{pH}$ range of $2-5$. The solution $\mathrm{pH}$ was adjusted by adding $0.1 \mathrm{M} \mathrm{NaOH}$ or $0.1 \mathrm{M}$ $\mathrm{HCl}$ solutions. To study the effect of adsorbent dose, the dose was varied from 0.2 to $1.8 \mathrm{~g} \mathrm{~L}^{-1}$ at a $\mathrm{pH}$ of 4 and an adsorption time of $60 \mathrm{~min}$. The sorption kinetics were evaluated at various sorption times $(20-120 \mathrm{~min})$ with an initial 
zinc concentration of $25 \mathrm{ppm}$ and an adsorbent dose of $1.4 \mathrm{~g}$ $\mathrm{L}^{-1}$ at a $\mathrm{pH}$ of 4 . After being stirred continuously for a certain amount of time, the solutions were collected and the equilibrium concentration of zinc ion was determined using an atomic absorption spectrometer (ContraAA800D, Germany). The adsorption capacity $\left(\mathrm{mg} \mathrm{g}^{-1}\right)$ and the removal percentage (\%) of metal ion were calculated by the following equation $[11,29]$ :

$$
\begin{array}{r}
q_{e}=\frac{\left(C_{0}-C_{e}\right) V}{m}, \\
\operatorname{removal}(\%)=\frac{C_{0}-C_{e}}{C_{0}} \times 100,
\end{array}
$$

where $C_{0}$ and $C_{\mathrm{e}}\left(\mathrm{mg} \mathrm{L}^{-1}\right)$ are the initial concentration and the equilibrium concentration of $\mathrm{Zn}$ (II), respectively, while $m(g)$ is the adsorbent mass and $\mathrm{V}(L)$ is the solution volume.

\section{Results and Discussion}

3.1. Characterizations of the Material. The crystal structure of the obtained $\mathrm{AC} / \mathrm{Fe}_{3} \mathrm{O}_{4}$ composite was determined using the XRD technique. The XRD pattern of the composite (Figure 2) was analyzed using JCPDS, with all the peaks matching the reported magnetite pattern (PDF no. 01-0716336). The pattern appeared in the form of broad bands, possibly due to the low iron content and/or the small crystalline size of the magnetite formation dispersed over the carbon matrix. The existence of magnetite in the composite was also confirmed by the vibration peak of $\mathrm{Fe}-\mathrm{O}$ at about $584 \mathrm{~cm}^{-1}$ [30] in the FTIR spectrum (Figure 3). The characteristic vibration peaks corresponding to AC were clearly observable, including the hydroxyl-OH group $\left(3,635 \mathrm{~cm}^{-1}\right)$, carbonyl $\mathrm{C}=\mathrm{O}\left(1,722 \mathrm{~cm}^{-1}\right), C=\mathrm{C}\left(1,573 \mathrm{~cm}^{-1}\right)$, and $\mathrm{C}-\mathrm{O}$ $\left(1,260 \mathrm{~cm}^{-1}\right)$.

In addition to the structure and functional groups, surface morphology of materials is known to play an important role in the application processes [31]. TEM and SEM-EDX techniques were then employed to study the morphology and the distribution of each component in the composites. The qualitative analysis conducted using SEM (Figure 4(a)) revealed that the composite possessed a rough and irregular surface. The presence of $\mathrm{Fe}$ and $\mathrm{O}$ elements by elemental mapping using EDX is presented in Figures 4(b) and $4(\mathrm{c})$, respectively. These elements appeared throughout the composite, indicating a high dispersion of $\mathrm{Fe}_{3} \mathrm{O}_{4}$ over the material. The TEM images (Figures 5(a) and 5(b)) further confirmed the attachment of $\mathrm{Fe}_{3} \mathrm{O}_{4}$ to the AC matrix.

The surface area of the sample was determined using nitrogen adsorption-desorption analysis. The composite possessed a specific surface area of $72.23 \mathrm{~m}^{2} \mathrm{~g}^{-1}$ according to the Brunauer-Emmett-Teller (BET) method. This result is similar to the specific surface area of $70.06 \mathrm{~m}^{2} \mathrm{~g}^{-1}$ of the AC/ iron oxide composite obtained by Wongcharee et al. [32]. In agreement with Wongcharee et al. [32], these low values may owe to the filling of magnetite particles into some pore structures of AC. This may reduce the adsorption capacity of parent AC; however, the dispersion of the magnetic material

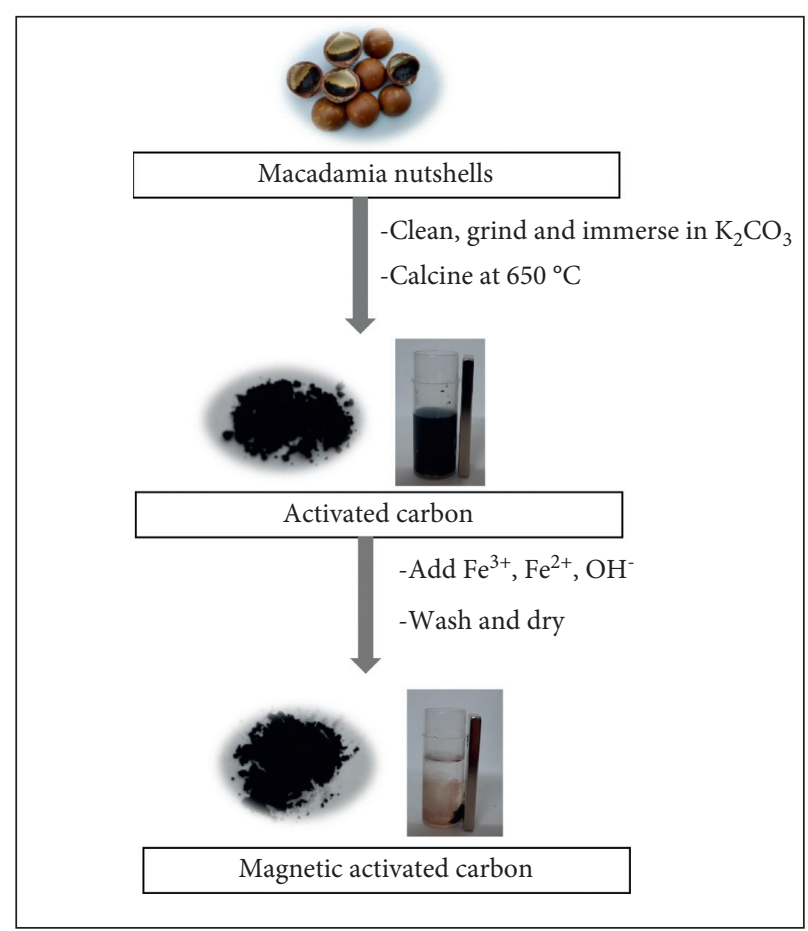

Figure 1: Schematic representation of the synthesis of magnetic AC derived from macadamia nutshells.

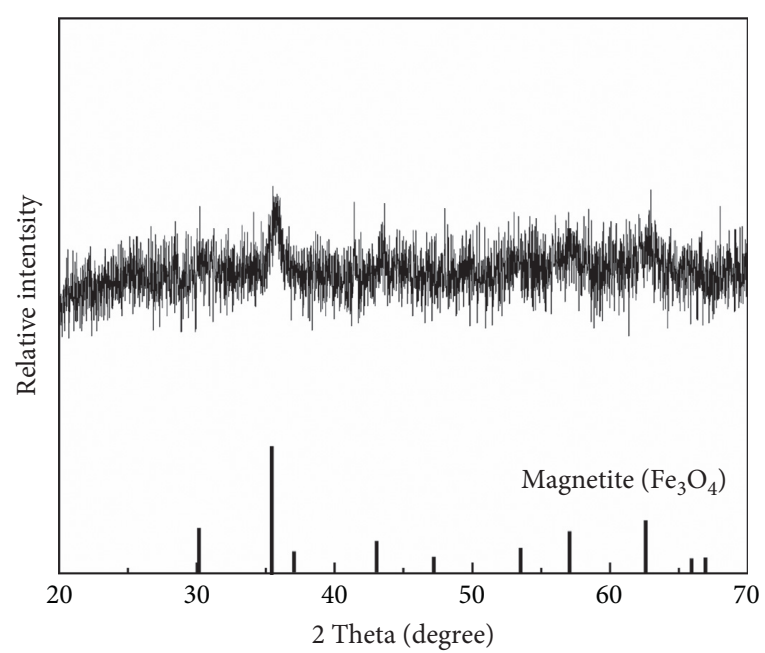

FIGURE 2: XRD pattern of the $\mathrm{AC} / \mathrm{Fe}_{3} \mathrm{O}_{4}$ composite.

over the AC matrix could be desirable for a convenient separation.

In order to examine the magnetic properties of the composite, the magnetization hysteresis curve was recorded at room temperature (Figure 6). The nearly zero values of magnetic remanence and coercivity in the hysteresis exhibited the superparamagnetic property of the composite [11]. Such behavior is to be expected for spherical magnetite nanoparticles with a diameter of approximately $10 \mathrm{~nm}$ [33]. The saturation magnetization $\left(M_{\mathrm{s}}\right)$ was found to be $38.2 \mathrm{emu} \mathrm{g}^{-1}$. The superparamagnetic nature allowed the convenient adsorbent recovery of the spent composite 


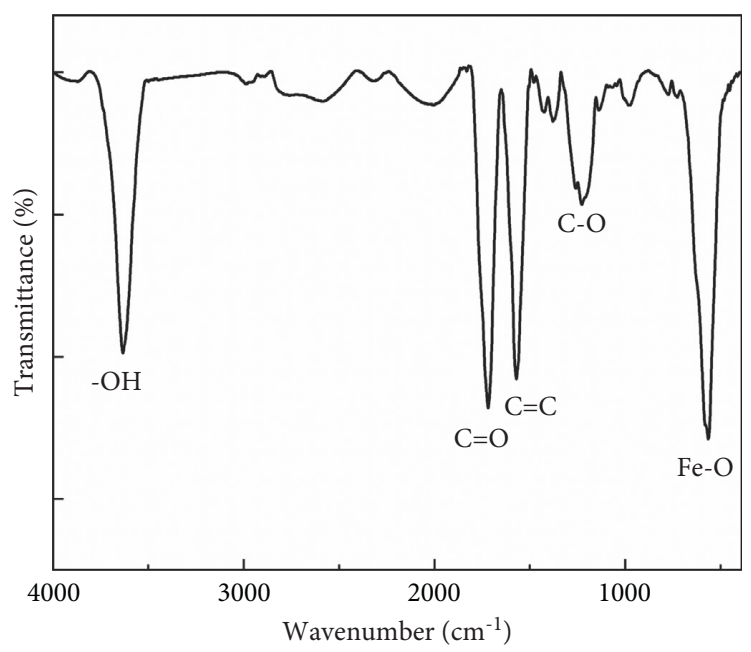

FIgURE 3: FTIR spectrum of the $\mathrm{AC} / \mathrm{Fe}_{3} \mathrm{O}_{4}$ composite.

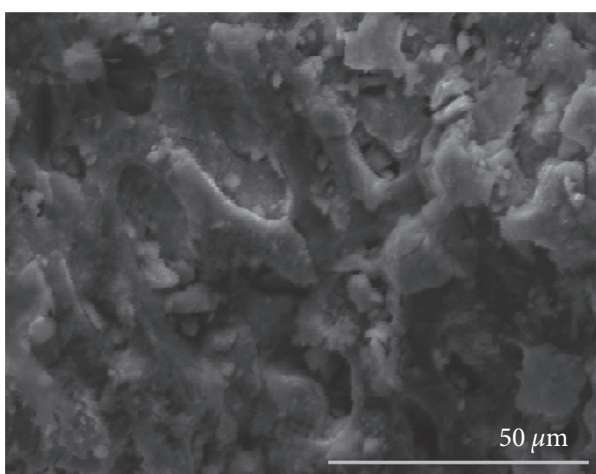

(a)

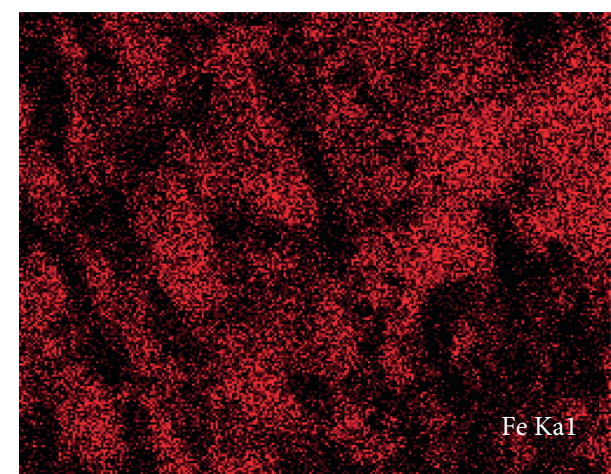

(b)

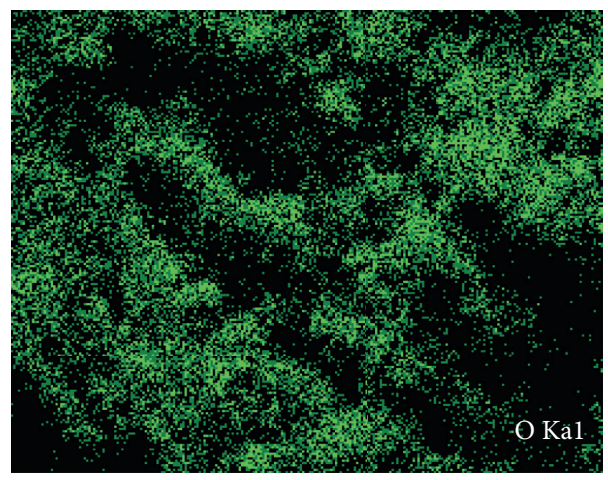

(c)

FIgURE 4: SEM image (a) and EDX elemental mapping of $\mathrm{Fe}(\mathrm{b})$ and $\mathrm{O}$ (c) of the $\mathrm{AC} / \mathrm{Fe}_{3} \mathrm{O}_{4}$ composite.

from treated media using an external magnetic field. These results indicate that the $\mathrm{AC} / \mathrm{Fe}_{3} \mathrm{O}_{4}$ composite was prepared successfully.

3.2. Sorption Study. The adsorption of zinc (II) ion on the $\mathrm{AC} / \mathrm{Fe}_{3} \mathrm{O}_{4}$ composite was examined using batch experiments. The adsorption properties of the sorbent including the effects of initial $\mathrm{pH}$, adsorbent dose, adsorption kinetics, and adsorption mechanism were investigated.
3.2.1. Effect of $\mathrm{pH}$. $\mathrm{pH}$ is an important variable influencing the binding of heavy metal ions onto the surfaces of adsorbents [34]. The effect of $\mathrm{pH}$ on the adsorption of zinc (II) ion was therefore studied in the initial $\mathrm{pH}$ range of 2.0-5.0. The increase in $\mathrm{pH}$ from 2.0 to 3.5 was seen to lead to a rapid enhancement in the extent of metal ion removal (Figure 7). The further increase in $\mathrm{pH}$ from 3.5 to 5.0 caused a slow enhancement in the removal percentage, reaching a maximum value at a $\mathrm{pH}$ of 4.0. These behaviors can be explained based on the interaction between the adsorbent and the 


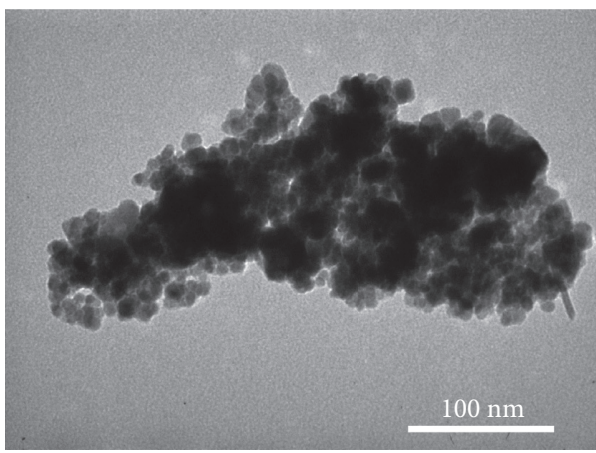

(a)

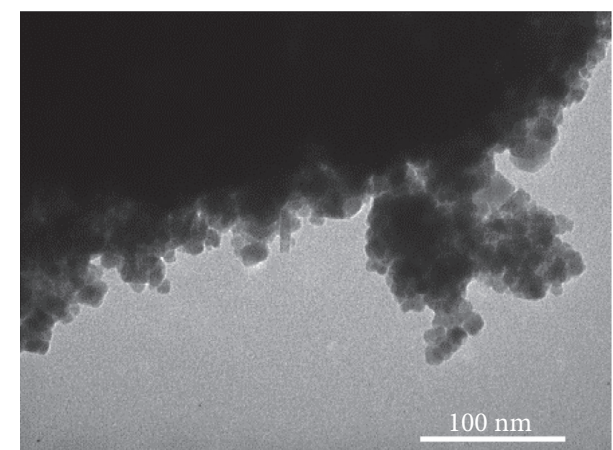

(b)

Figure 5: TEM images of the $\mathrm{AC}-\mathrm{Fe}_{3} \mathrm{O}_{4}$ composite (a) and (b).

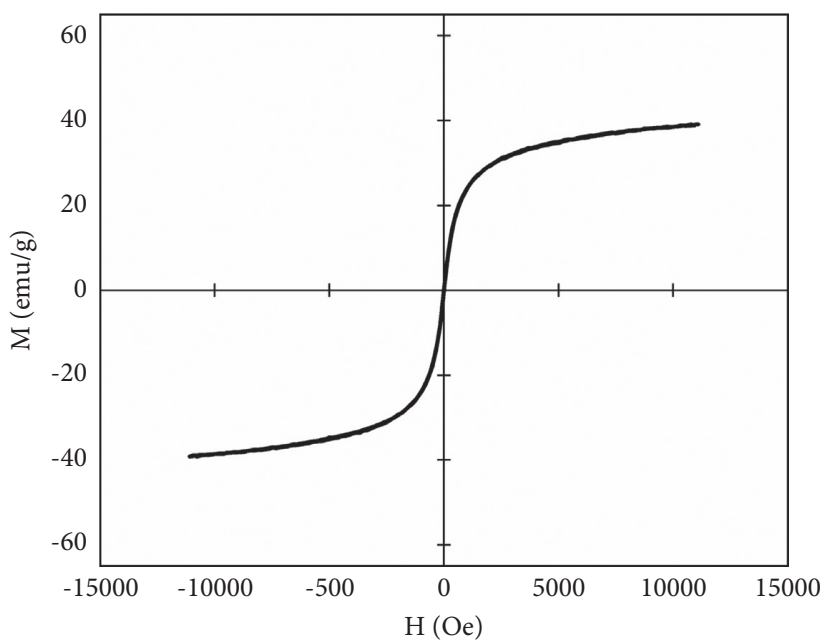

Figure 6: Magnetization hysteresis curve of the $\mathrm{AC} / \mathrm{Fe}_{3} \mathrm{O}_{4}$ composite.

adsorbate that the oxygenic functional groups of $\mathrm{AC} / \mathrm{Fe}_{3} \mathrm{O}_{4}$ composites can interact with $\mathrm{Zn}^{2+}$ to form metal complexes [35]. At low $\mathrm{pH}$, the $\mathrm{H}^{+}$ion may compete with $\mathrm{Zn}^{2+}$ and occupy the surface of the adsorbent, thereby causing the metal adsorption to become more unfavorable. Surface complexation is expected to be predominant mechanism in the adsorption process in this study. The mechanism of cadmium adsorption will be discussed hereafter.

3.2.2. Effect of Adsorbent Dose. Studying the effect of adsorbent dose on adsorption plays a crucial role in large-scale applications. It is valuable not only for minimizing adsorption costs but also for avoiding the excessive use of adsorbents during wastewater treatment [36]. The effect of adsorbent dose on the removal of zinc ion is demonstrated in Figure 8 . The removal percentage capacity enhanced as the dose increased from $0.2 \mathrm{~g} \mathrm{~L}^{-1}$ to $1.4 \mathrm{~g} \mathrm{~L}^{-1}$. This behavior can be attributed to the increase in the number of accessible active sites for zinc (II) ion. When the adsorbent dose further increased from $1.4 \mathrm{~g} \mathrm{~L}^{-1}$ to $1.8 \mathrm{~g} \mathrm{~L}^{-1}$, there was no statistically significant difference in removal efficiencies (one-way analysis of variance, $P=0.99$ ) at a $95 \%$ confidence interval $(\alpha=0.05)$. This could be explained by the agglomeration of sorbent caused from high dose of sorbent in solution, resulting in a saturation of active sites and a surface equilibrium state of the adsorption [37].

3.2.3. Adsorption Kinetics. The field of adsorption kinetics studies changes in the particular adsorbent/adsorbate system over time that can determine the reaction rate, the factors that affect the rate, and the probable mechanisms involved [38]. The adsorption of $\mathrm{Zn}^{2+}$ ion by the $\mathrm{AC} / \mathrm{Fe}_{3} \mathrm{O}_{4}$ composite was observed at different contact times, varying from $20 \mathrm{~min}$ to $120 \mathrm{~min}$ (Figure 9). In the first $40 \mathrm{~min}$, the adsorption process occurred rapidly, reaching equilibrium after $60 \mathrm{~min}$ at $298 \mathrm{~K}$

The obtained experimental kinetics data were analyzed using pseudo-first-order kinetics equation (2), pseudo-second-order kinetics equation (3), the Elovich model equation (4), and the intraparticle diffusion kinetics model equation (5) $[11,39,40]$.

$$
\begin{aligned}
\log \left(q_{e}-q_{t}\right) & =\log q_{e}-\frac{k_{1}}{2.303} t \\
\frac{t}{q_{t}} & =\frac{1}{k_{2} q_{e}^{2}}+\frac{t}{q_{e}}
\end{aligned}
$$




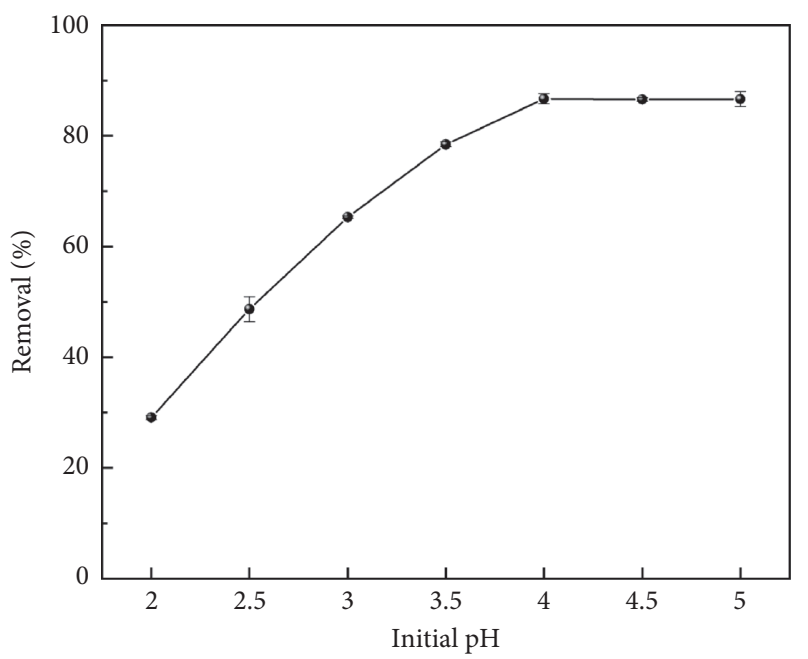

FIgure 7: The effect of initial $\mathrm{pH}$.

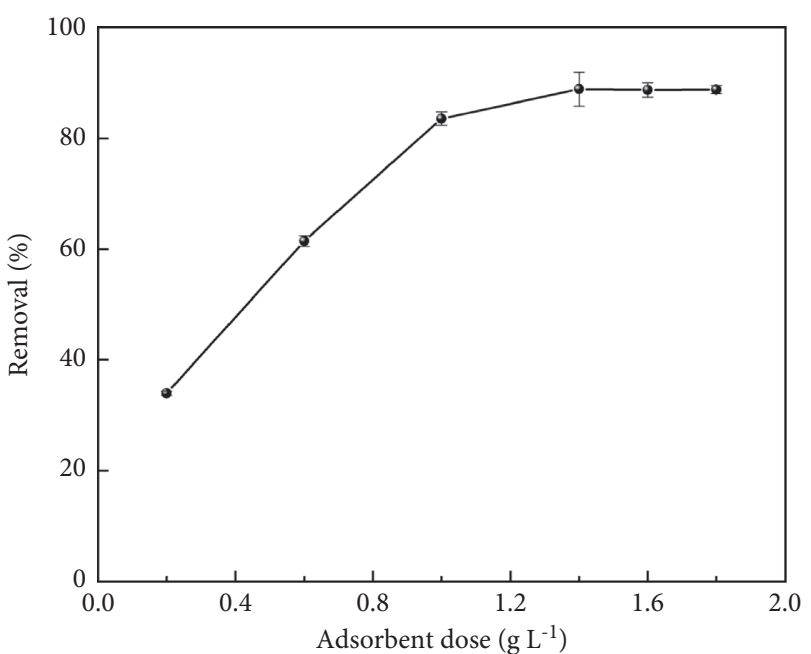

Figure 8: The effect of adsorbent dose.

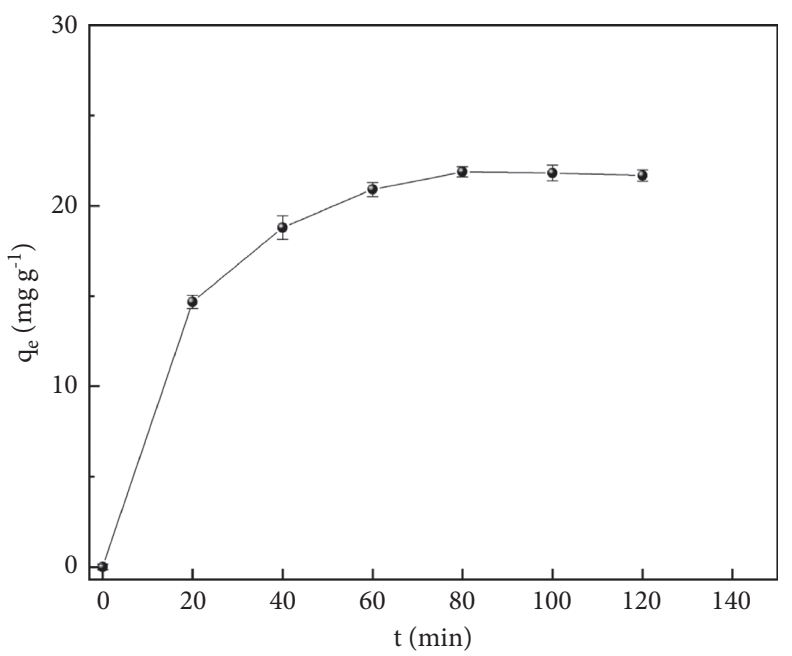

FIgURE 9: Zinc adsorption kinetics on the $\mathrm{AC} / \mathrm{Fe}_{3} \mathrm{O}_{4}$ composite.

$$
\begin{aligned}
& q_{1}=\frac{1}{\beta} \ln (\alpha \beta)+\frac{1}{\beta} \ln (t), \\
& q_{t}=k_{i} t^{1 / 2}+C,
\end{aligned}
$$

where $q_{\mathrm{e}}\left(\mathrm{mg} \mathrm{g}^{-1}\right)$ and $q_{\mathrm{t}}\left(\mathrm{mg} \mathrm{g}^{-1}\right)$ are the sorption capacities of a target at equilibrium and at a time $t$, respectively, and $k_{1}$ $\left(\mathrm{min}^{-1}\right), k_{2}\left(\mathrm{~g} \mathrm{mg}^{-1} \mathrm{~min}^{-1}\right), \alpha\left(\mathrm{mg} \mathrm{g}^{-1} \min ^{-1}\right)$, and $k_{\mathrm{i}}(\mathrm{mg}$ $\left.\mathrm{g} \mathrm{min}^{-0.5}\right)$ are the rate constants of the pseudo-first-order, the pseudo-second-order, the Elovich kinetics model equation, and intraparticle diffusion, respectively. $\beta\left(\mathrm{mg} \mathrm{g}^{-1}\right)$ is the desorption constant in the Elovich equation, and $\mathrm{C}$ is related to the boundary layer thickness.

The linear plotting of the four models is presented in Figure 10, and the obtained kinetics model parameters are listed in Table 1. The Elovich model was found to be the best fit of the experimental data, followed closely by the pseudo-second-order model. The pseudo-first-order and intraparticle diffusion kinetics models did not fit well with the kinetics data. The close values of adsorption capacity at equilibrium calculated using the pseudo-second-order model $\left(q_{\mathrm{e}, \mathrm{cal}}=22.73 \mathrm{mg}\right.$ $\left.\mathrm{g}^{-1}\right)$ and the experimental value $\left(q_{\mathrm{e}, \exp }=24.02 \mathrm{mg} \mathrm{g}^{-1}\right)$ indicated the good fit of the model to the experimental data. The initial rate $\left(h=k_{2} q_{\mathrm{e}}{ }^{2}\right)$ of $\mathrm{Zn}^{2+}$ adsorption on $\mathrm{ACP} / \mathrm{Fe}_{3} \mathrm{O}_{4}$ was calculated to be $4.18 \mathrm{mg} \mathrm{g}^{-1} \mathrm{~min}^{-1}$. The good fit of the kinetics data with the Elovich model is suitable for a system with a heterogeneous adsorbing surface, like the $\mathrm{AC} / \mathrm{Fe}_{3} \mathrm{O}_{4}$ composite in this study. Moreover, this model is related to chemisorption, indicating that the surface complexation can be a predominant mechanism of the adsorption process.

The optimum adsorption conditions and removal efficiency of $\mathrm{AC} / \mathrm{Fe}_{3} \mathrm{O}_{4}$ composite in $\mathrm{Zn}^{2+}$ ion adsorption are compared with previously reported studies (Table 2). It can be observed that the results obtained in this study are comparable with the literature under similar conditions. Moreover, the adsorbent in this study has the advantage of possessing higher pseudo-second-order rate constant compared with many other materials. These results make $\mathrm{AC} / \mathrm{Fe}_{3} \mathrm{O}_{4}$ composite an interesting material with respect to 


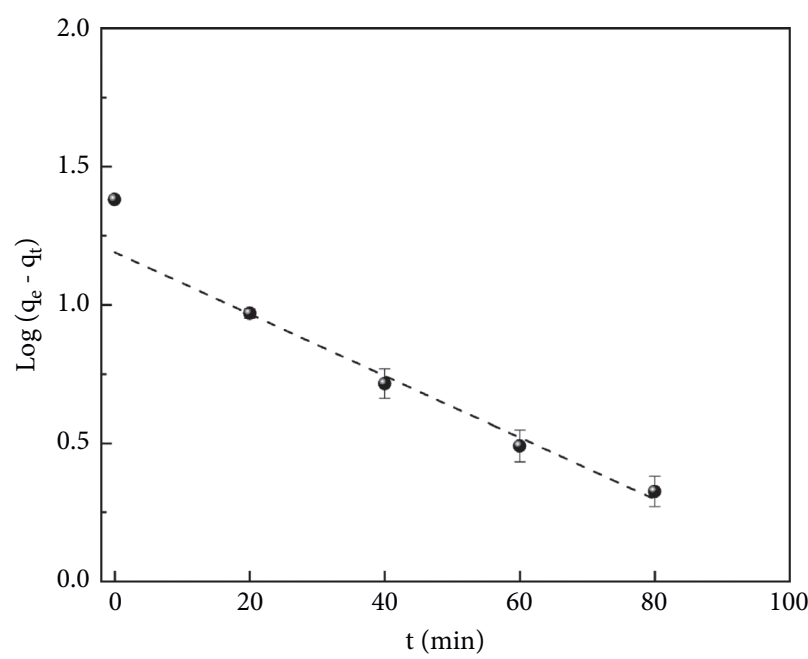

(a)

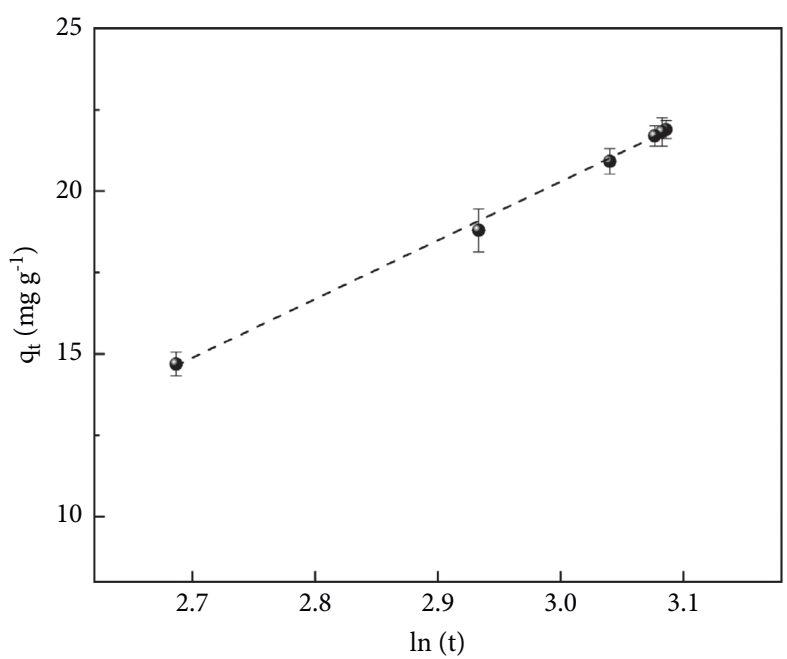

(c)

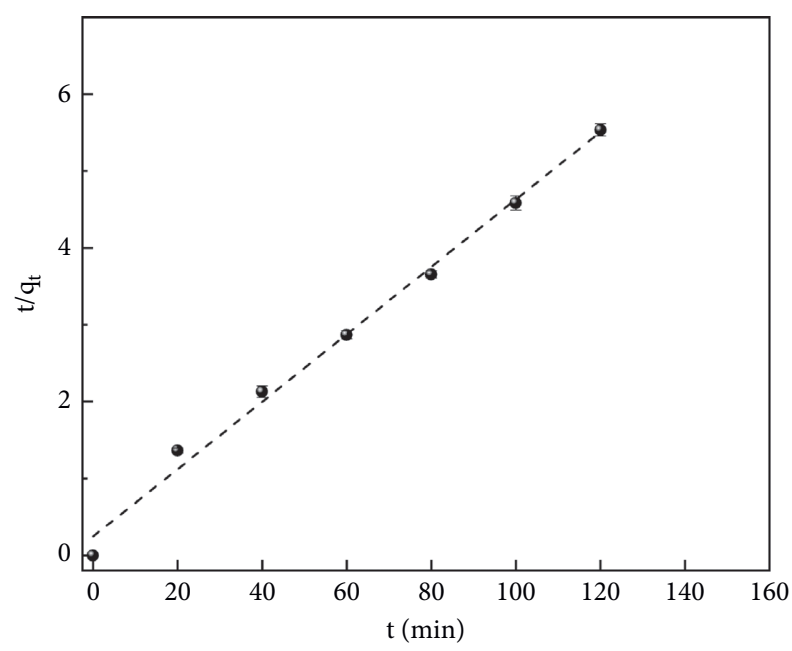

(b)

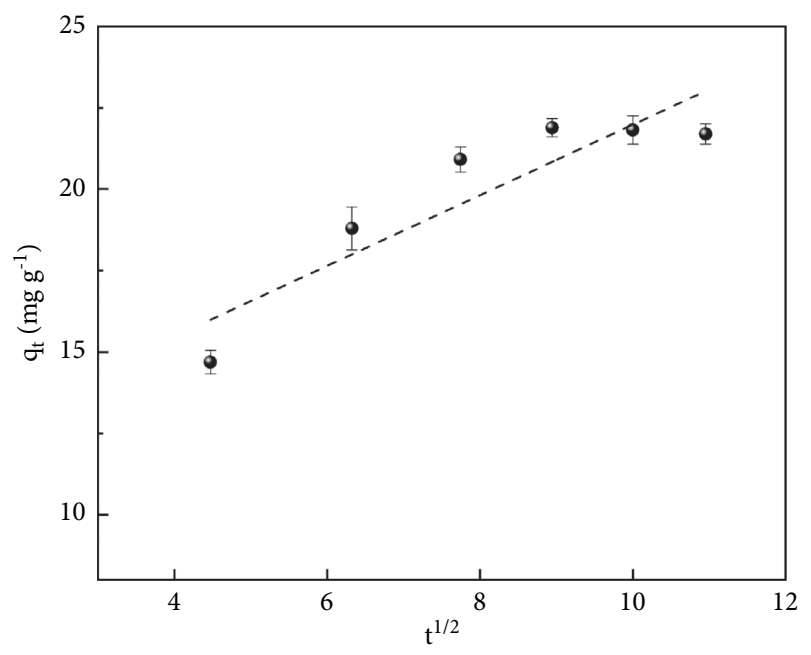

(d)

Figure 10: Pseudo-first-order model (a), pseudo-second-order model (b), Elovich kinetics model (c), and intraparticle diffusion kinetics model (d) for the adsorption of $\mathrm{Zn}^{2+}$ ion by the $\mathrm{AC} / \mathrm{Fe}_{3} \mathrm{O}_{4}$ composite.

TABLE 1: Kinetics model parameters for the adsorption of $\mathrm{Zn}^{2+}$ ion by the $\mathrm{ACP} / \mathrm{Fe}_{3} \mathrm{O}_{4}$ composite.

\begin{tabular}{|c|c|c|c|}
\hline Models & & and regressi & \\
\hline Deoude firctorder & $k_{1}\left(\min ^{-1}\right)$ & $q_{\mathrm{e}}\left(\mathrm{mg} \mathrm{g}^{-1}\right)$ & $R^{2}$ \\
\hline Pseudo-first-order & 0.030 & 19.50 & 0.970 \\
\hline & $k_{2}\left(\mathrm{~g} \mathrm{mg}^{-1} \mathrm{~min}^{-1}\right)$ & $q_{\mathrm{e}}\left(\mathrm{mg} \mathrm{g}^{-1}\right)$ & $R^{2}$ \\
\hline Pseudo-second-order & 0.0081 & 22.73 & 0.993 \\
\hline Elovich & $\alpha\left(\mathrm{mg} \mathrm{g}^{-1} \min ^{-1}\right)$ & $\beta\left(\mathrm{mg} \mathrm{g}^{-1}\right)$ & $R^{2}$ \\
\hline Elovich & 2.76 & 0.055 & 0.998 \\
\hline Intronorticle diffucion & $k_{\mathrm{i}}\left(\mathrm{mg} g \min ^{-0.5}\right)$ & $\mathrm{C}$ & $R^{2}$ \\
\hline Intraparticle diffusion & 1.07 & 11.32 & 0.824 \\
\hline
\end{tabular}

its environmentally friendliness, cost-effectiveness, convenient separation, and relatively high adsorption efficiency.

\subsubsection{Proposed Mechanism of the Adsorption Process.} Depending on the properties of metal ions, surface charges, pore sizes, and functional groups of adsorbents, there may be different interactions governing adsorption of heavy metals on AC-based materials [45]. In this study, the results obtained supported the hypothesis that surface complexation should be the predominant mechanism of the adsorption process. A proposed mechanism is presented in Figure 11. $\mathrm{AC} / \mathrm{Fe}_{3} \mathrm{O}_{4}$ composite contains carboxylic and hydroxyl groups that can serve as ligand-like surface functional 
TABLE 2: Comparison of adsorption conditions and adsorption efficiency of various materials for $\mathrm{Zn}^{2+}$ removal.

\begin{tabular}{|c|c|c|c|c|c|c|c|c|c|}
\hline \multirow[b]{2}{*}{ Materials } & \multirow[b]{2}{*}{$\mathrm{pH}$} & \multirow{2}{*}{$\begin{array}{c}\text { Adsorbent } \\
\text { dosage }\left(\mathrm{g} \mathrm{L}^{-1}\right)\end{array}$} & \multirow{2}{*}{$\begin{array}{l}\text { Contact } \\
\text { time }(\mathrm{min})\end{array}$} & \multirow{2}{*}{$\begin{array}{l}\text { Initial concentration } \\
\text { of } \mathrm{Zn}^{2+}(\mathrm{ppm})\end{array}$} & \multirow{2}{*}{$\begin{array}{c}\text { Adsorption } \\
\text { capacity }\left(\mathrm{mg} \mathrm{g}^{-1}\right)\end{array}$} & \multirow{2}{*}{$\begin{array}{l}\operatorname{Re} \\
(\%)\end{array}$} & \multicolumn{2}{|c|}{$\begin{array}{l}\text { Pseudo-second- } \\
\text { order parameters }\end{array}$} & \multirow[b]{2}{*}{ Ref. } \\
\hline & & & & & & & $\begin{array}{l}q_{\mathrm{e}, \mathrm{cal}} \\
(\mathrm{mg} \\
\left.\mathrm{g}^{-1}\right)\end{array}$ & $\begin{array}{c}k_{2}\left(\mathrm{~g} \mathrm{mg}^{-1}\right. \\
\left.\min ^{-1}\right)\end{array}$ & \\
\hline Zeolites & - & 5 & 180 & 200 & 36.76 & - & 34.72 & 0.002 & {$[41]$} \\
\hline Fish bone & 5.0 & 18 & 720 & 20 & - & 98 & 1.93 & $0.00023^{*}$ & {$[42]$} \\
\hline $\begin{array}{l}\text { Palm oil mill } \\
\text { effluent-based AC }\end{array}$ & 5.5 & $4^{*}$ & 50 & 350 & 59.88 & - & 29.50 & 0.0020 & {$[43]$} \\
\hline Tire-derived AC & - & $4^{*}$ & $360^{*}$ & 500 & 71.9 & - & 50.25 & 0.0057 & {$[35]$} \\
\hline Commercial AC & - & $50^{*}$ & $1440^{*}$ & 500 & 14.0 & - & 5.57 & 0.0019 & {$[35]$} \\
\hline $\mathrm{AC} / \mathrm{Fe}_{3} \mathrm{O}_{4}$ & 4.0 & $6^{*}$ & 180 & 10 & - & 70.5 & - & - & {$[44]$} \\
\hline $\mathrm{AC} / \mathrm{Fe}_{3} \mathrm{O}_{4}$ & $4.0-5.0$ & 1.4 & 60 & 25 & - & 90 & 22.73 & 0.0081 & $\begin{array}{l}\text { This } \\
\text { study }\end{array}$ \\
\hline
\end{tabular}

${ }^{*}$ calculated from the published papers.

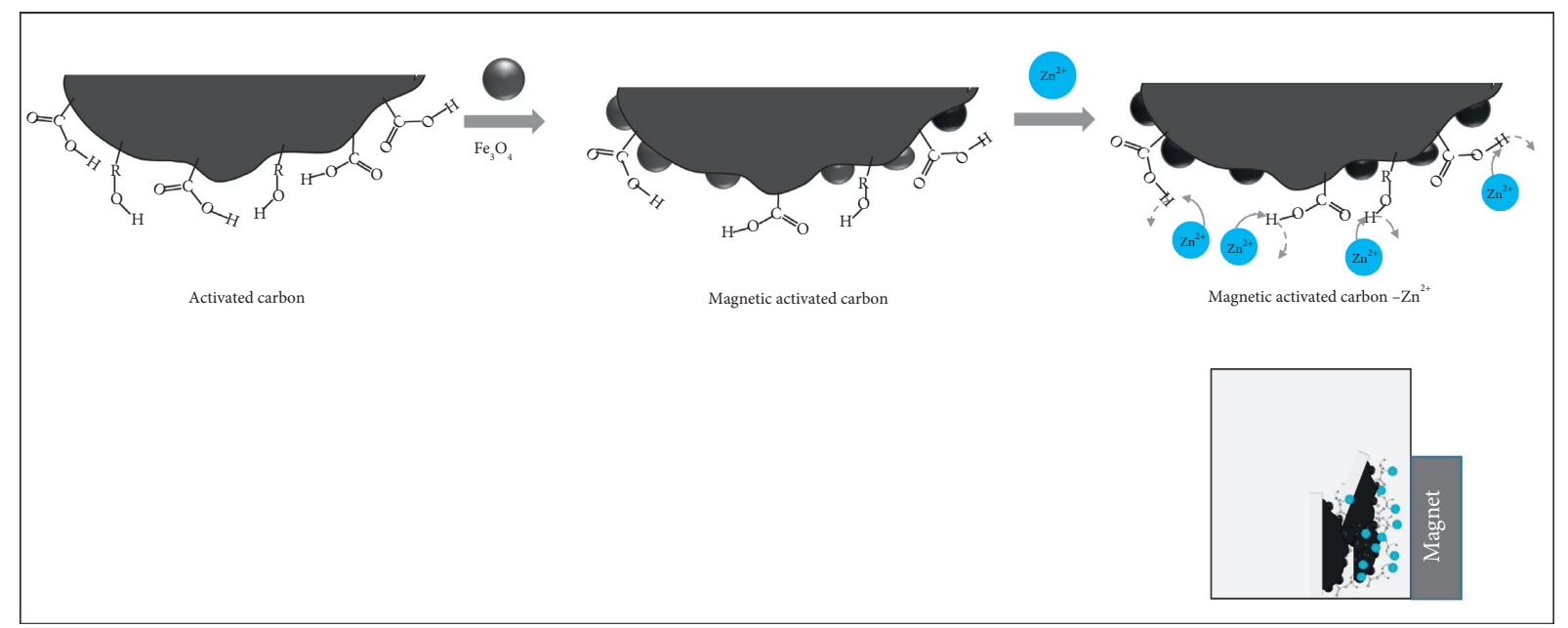

Figure 11: A proposed mechanism of the adsorption process.

groups. These oxygenic functional groups can interact with divalent zinc (II) ion to form specific metal complexes. This facilitates the stabilization of $\mathrm{Zn}^{2+}$ on the surface of the adsorbent and can then be recovered by an external magnet.

\section{Conclusions}

The magnetic AC derived from macadamia nutshell residue was successfully prepared and utilized for the removal of zinc (II) ion in an aqueous solution. $\mathrm{Fe}_{3} \mathrm{O}_{4}$ was found to be attached to the carbon matrix, forming a magnetically separable adsorbent. The adsorption capacity was affected by the initial $\mathrm{pH}$, the adsorbent dose, and the sorption time. It reached a maximum value at $\mathrm{pH}$ of 4 , an adsorbent dose of $1.4 \mathrm{~g} \mathrm{~L}^{-1}$, and a sorption time of $1 \mathrm{~h}$. The kinetics data followed the Elovich model and the pseudo-second-order model, indicating that chemisorption could occur on the heterogeneous surface of the solid adsorbent. Surface complexation mechanism was then proposed to be responsible for the adsorption. This study has provided information about the properties and the feasibility of zinc (II) ion removal of magnetic AC derived from macadamia nutshell residue. This composite is a promising adsorbent for being low-cost, environmentally friendly, and magnetically separable. Its utilization in wastewater treatments also provides opportunity for converting the leftover agricultural waste to valuable materials.

\section{Data Availability}

The data used to support the findings of this study are included within the article.

\section{Conflicts of Interest}

The authors declare that they have no conflicts of interest.

\section{Acknowledgments}

This research was funded by Thu Dau Mot University under grant number DT.21.1-033.

\section{References}

[1] X. Guo, L. Kong, Y. Ruan et al., "Green and facile synthesis of cobalt-based metal-organic frameworks for the efficient 
removal of Congo red from aqueous solution," Journal of Colloid and Interface Science, vol. 578, pp. 500-509, 2020.

[2] F. O. Ajibade, B. Adelodun, K. H. Lasisi et al., "Environmental pollution and their socioeconomic impacts," Microbe Mediated Remediation of Environmental Contaminants, Woodhead Publishing, Sawston,UK, pp. 321-354, 2021.

[3] M. Mao, T. Yan, J. Shen, J. Zhang, and D. Zhang, "Capacitive removal of heavy metal ions from wastewater via an electroadsorption and electro-reaction coupling process," Environmental Science \& Technology, vol. 55, no. 5, pp. 3333-3340, 2021.

[4] S. Li, Y. Li, Z. Fu, L. Lu, J. Cheng, and Y. Fei, "A 'top modification' strategy for enhancing the ability of a chitosan aerogel to efficiently capture heavy metal ions," Journal of Colloid and Interface Science, vol. 594, pp. 141-149, 2021.

[5] A. Saravanan, P. S. Kumar, and A. A. Renita, "Hybrid synthesis of novel material through acid modification followed ultrasonication to improve adsorption capacity for zinc removal," Journal of Cleaner Production, vol. 172, pp. 92-105, 2018.

[6] I. Zinicovscaia, N. Yushin, M. Shvetsova, and M. Frontasyeva, "Zinc removal from model solution and wastewater by Arthrospira (Spirulina) Platensis biomass," International Journal of Phytoremediation, vol. 20, no. 9, pp. 901-908, 2018.

[7] A. Jakóbik-Kolon, J. Bok-Badura, K. Karoń, K. Mitko, and A. Milewski, "Hybrid pectin-based biosorbents for zinc ions removal," Carbohydrate Polymers, vol. 169, pp. 213-219, 2017.

[8] Q. Chen, Y. Yao, X. Li, J. Lu, J. Zhou, and Z. Huang, "Comparison of heavy metal removals from aqueous solutions by chemical precipitation and characteristics of precipitates," Journal of Water Process Engineering, vol. 26, pp. 289-300, 2018.

[9] M. Zheng, Z. Sun, H. Han, Z. Zhang, W. Ma, and C. Xu, "Enhanced coagulation coupled with heavy metal capturing for heavy metals removal from coal gasification brine and a novel mathematical model," Journal of Water Process Engineering, vol. 40, pp. 101954-101963, 2021.

[10] C. Liu, T. Wu, P.-C. Hsu et al., "Direct/alternating current electrochemical method for removing and recovering heavy metal from water using graphene oxide electrode," ACS Nano, vol. 13, no. 6, pp. 6431-6437, 2019.

[11] T. T. T. L. Hoang, F. Unob, S. Suvokhiaw, and N. Sukpirom, "One-pot synthesis of amorphous calcium phosphate/Fe3O4 composites and the application in the removal of cadmium," Journal of Environmental Chemical Engineering, vol. 8, no. 2, pp. 103653-103663, 2020.

[12] F. Fu and Q. Wang, "Removal of heavy metal ions from wastewaters: a review," Journal of Environmental Management, vol. 92, no. 3, pp. 407-418, 2011.

[13] M. Majdoub, A. Amedlous, Z. Anfar, A. Jada, and N. El Alem, "Engineering of amine-based binding chemistry on functionalized graphene oxide/alginate hybrids for simultaneous and efficient removal of trace heavy metals: towards drinking water," Journal of Colloid and Interface Science, vol. 589, pp. 511-524, 2021.

[14] X. Shi, L. Kang, J. Hong et al., "Strong selectivity and high capacity in the adsorption of as (V) from wastewater by glycine-modified $\mathrm{Fe} / \mathrm{Cu}$-layered double hydroxides," Journal of Alloys and Compounds, vol. 865, pp. 158956-158964, 2021.

[15] E. A. Abdelrahman, Y. G. Abou El-Reash, H. M. Youssef, Y. H. Kotp, and R. M. Hegazey, "Utilization of rice husk and waste aluminum cans for the synthesis of some nanosized zeolite, zeolite/zeolite, and geopolymer/zeolite products for the efficient removal of $\mathrm{Co}(\mathrm{II}), \mathrm{Cu}(\mathrm{II})$, and $\mathrm{Zn}$ (II) ions from aqueous media," Journal of Hazardous Materials, vol. 401, pp. 123813-123832, 2021.

[16] J. Wen and X. Hu, "Metal selectivity and effects of co-existing ions on the removal of $\mathrm{Cd}, \mathrm{Cu}, \mathrm{Ni}$, and $\mathrm{Cr}$ by ZIF-8-EGCG nanoparticles," Journal of Colloid and Interface Science, vol. 589, pp. 578-586, 2021.

[17] Z. Ma, H. Ji, Y. Teng et al., "Engineering and optimization of nano- and mesoporous silica fibers using sol-gel and electrospinning techniques for sorption of heavy metal ions," Journal of Colloid and Interface Science, vol. 358, no. 2, pp. 547-553, 2011.

[18] J. Zhao, L. Yu, H. Ma, F. Zhou, K. Yang, and G. Wu, "Corn stalk-based activated carbon synthesized by a novel activation method for high-performance adsorption of hexavalent chromium in aqueous solutions," Journal of Colloid and Interface Science, vol. 578, pp. 650-659, 2020.

[19] Z. S. Liu, "Control of heavy metals during incineration using activated carbon fibers," Journal of Hazardous Materials, vol. 142, no. 1-2, pp. 506-511, 2007.

[20] M. J. Martin, A. Artola, M. D. Balaguer, and M. Rigola, "Activated carbons developed from surplus sewage sludge for the removal of dyes from dilute aqueous solutions," Chemical Engineering Journal, vol. 94, no. 3, pp. 231-239, 2003.

[21] Ö. Gerçel and H. F. Gerçel, "Adsorption of lead(II) ions from aqueous solutions by activated carbon prepared from biomass plant material of Euphorbia rigida," Chemical Engineering Journal, vol. 132, no. 1-3, pp. 289-297, 2007.

[22] M. T. Dao, T. T. T. Nguyen, X. D. Nguyen et al., "Toxic metal adsorption from aqueous solution by activated biochars produced from macadamia nutshell waste," Sustainability, vol. 12, no. 19, pp. 7909-1919, 2020.

[23] G. E. J. Poinern, G. Senanayake, N. Shah, X. N. Thi-Le, G. M. Parkinson, and D. Fawcett, "Adsorption of the aurocyanide, complex on granular activated carbons derived from macadamia nut shells-a preliminary study," Minerals Engineering, vol. 24, no. 15, pp. 1694-1702, 2011.

[24] B. S. Inbaraj, K. Sridhar, and B.-H. Chen, "Removal of polycyclic aromatic hydrocarbons from water by magnetic activated carbon nanocomposite from green tea waste," Journal of Hazardous Materials, vol. 415, pp. 125701-125715, 2021.

[25] F. Zhang, H. Zhang, R. Chen et al., "Mussel-inspired antifouling magnetic activated carbon for uranium recovery from simulated seawater," Journal of Colloid and Interface Science, vol. 534, pp. 172-182, 2019.

[26] J. Kaur, M. Kaur, M. K. Ubhi, N. Kaur, and J.-M. Greneche, "Composition optimization of activated carbon-iron oxide nanocomposite for effective removal of Cr(VI)ions," Materials Chemistry and Physics, vol. 258, pp. 124002-124014, 2021.

[27] T. M. Dao and T. Le Luu, "Synthesis of activated carbon from macadamia nutshells activated by $\mathrm{H} 2 \mathrm{SO} 4$ and $\mathrm{K} 2 \mathrm{CO} 3$ for methylene blue removal in water," Bioresource Technology Reports, vol. 12, pp. 100583-100588, 2020.

[28] Z. Han, B. Sani, W. Mrozik et al., "Magnetite impregnation effects on the sorbent properties of activated carbons and biochars," Water Research, vol. 70, pp. 394-403, 2015.

[29] F. Almomani, R. Bhosale, M. Khraisheh, A. kumar, and T. Almomani, "Heavy metal ions removal from industrial wastewater using magnetic nanoparticles (MNP)," Applied Surface Science, vol. 506, pp. 144924-144934, 2020.

[30] D. Maity, S.-G. Choo, J. Yi, J. Ding, and J. M. Xue, "Synthesis of magnetite nanoparticles via a solvent-free thermal 
decomposition route," Journal of Magnetism and Magnetic Materials, vol. 321, no. 9, pp. 1256-1259, 2009.

[31] Ş. Țălu, "Micro and nanoscale characterization of three dimensional surfaces," Basics and Applications, pp. 28-35, Napoca Star, Cluj-Napoca, Romania, 2015.

[32] S. Wongcharee, V. Aravinthan, L. Erdei, and W. Sanongraj, "Use of macadamia nut shell residues as magnetic nanosorbents," International Biodeterioration \& Biodegradation, vol. 124, pp. 276-287, 2017.

[33] H. Yang, S. Masse, H. Zhang, C. Hélary, L. Li, and T. Coradin, "Surface reactivity of hydroxyapatite nanocoatings deposited on iron oxide magnetic spheres toward toxic metals," Journal of Colloid and Interface Science, vol. 417, pp. 1-8, 2014.

[34] D. Ouyang, Y. Zhuo, L. Hu, Q. Zeng, Y. Hu, and Z. He, "Research on the adsorption behavior of heavy metal ions by porous material prepared with silicate tailings," Minerals, vol. 9, no. 5, pp. 291-306, 2019.

[35] R. Shahrokhi-Shahraki, C. Benally, M. G. El-Din, and J. Park, "High efficiency removal of heavy metals using tire-derived activated carbon vs commercial activated carbon: insights into the adsorption mechanisms," Chemosphere, vol. 264, pp. 128455-128469, 2021.

[36] S. S. Ray, R. Gusain, and N. Kumar, "Effect of reaction parameters on the adsorption," in Carbon Nanomaterial-Based Adsorbents for Water Purification, pp. 119-135, Elsevier, Amsterdam, 2020.

[37] B. N. Mahato, T. Krithiga, and M. A. Mary Thangam, "Rapid adsorption of $\mathrm{As}(\mathrm{V})$ from aqueous solution by $\mathrm{ZnO}$ embedded in mesoporous aluminosilicate nanocomposite adsorbent: parameter optimization, kinetic, and isotherms studies," Surfaces and Interfaces, vol. 23, pp. 100636-100644, 2021.

[38] V. G. Georgieva, L. Gonsalvesh, and M. P. Tavlieva, “Thermodynamics and kinetics of the removal of nickel (II) ions from aqueous solutions by biochar adsorbent made from agro-waste walnut shells," Journal of Molecular Liquids, vol. 312, pp. 112788-112799, 2020.

[39] A. Das, N. Bar, and S. K. Das, "Pb(II) adsorption from aqueous solution by nutshells, green adsorbent: adsorption studies, regeneration studies, scale-up design, its effect on biological indicator and MLR modeling," Journal of Colloid and Interface Science, vol. 580, pp. 245-255, 2020.

[40] S. Archana, B. K. Jayanna, A. Ananda, S. B.M, D. Pandiarajan, and H. B. Muralidhara, "Synthesis of nickel oxide grafted graphene oxide nanocomposites - a systematic research on chemisorption of heavy metal ions and its antibacterial activity," Environmental Nanotechnology, Monitoring \& Management, vol. 16, pp. 100486-100498, 2021.

[41] I. V. Joseph, L. Tosheva, and A. M. Doyle, "Simultaneous removal of $\mathrm{Cd}$ (II), $\mathrm{Co}$ (II), $\mathrm{Cu}$ (II), $\mathrm{Pb}$ (II), and $\mathrm{Zn}$ (II) ions from aqueous solutions via adsorption on FAU-type zeolites prepared from coal fly ash," Journal of Environmental Chemical Engineering, vol. 8, no. 4, pp. 103895-103903, 2020.

[42] H. K. Lim, T. T. Teng, M. H. Ibrahim, A. Ahmad, and H. T. Chee, "Adsorption and removal of zinc (II) from aqueous solution using powdered fish bones," APCBEE Procedia, vol. 1, pp. 96-102, 2012.

[43] G. A. Adebisi, Z. Z. Chowdhury, and P. A. Alaba, "Equilibrium, kinetic, and thermodynamic studies of lead ion and zinc ion adsorption from aqueous solution onto activated carbon prepared from palm oil mill effluent," Journal of Cleaner Production, vol. 148, pp. 958-968, 2017.

[44] W. Astuti, T. Sulistyaningsih, D. Prastiyanto, B. S. A. Purba, and R. Kusumawardani, "Synthesis of magnetically separable activated carbon from pineapple crown leaf for zinc ion removal," Materials Science Forum, vol. 1007, pp. 71-75, 2020.

[45] A. Kuroki, M. Hiroto, Y. Urushihara, T. Horikawa, K.-I. Sotowa, and J. R. A. Avila, "Adsorption mechanism of metal ions on activated carbon," Adsorption, vol. 25, no. 6, pp. 1251-1258, 2019. 